\title{
Research on the Tourism Cooperation Between Zhanjiang and Hainan
}

\author{
Luying Chen \\ Business School, Lingnan Normal University, Zhanjiang, China
}

Email address:

295387102@qq.com

\section{To cite this article:}

Luying Chen. Research on the Tourism Cooperation Between Zhanjiang and Hainan. International Journal of Management and Fuzzy Systems. Vol. 7, No. 1, 2021, pp. 11-17. doi: 10.11648/j.ijmfs.20210701.12

Received: April 16, 2021; Accepted: April 30, 2021; Published: May 14, 2021

\begin{abstract}
On April 13, 2018, Hainan and Guangdong jointly put forward the idea of accelerating the construction of Qiongzhou Strait economic belt and realizing integrated and coordinated development. As the southernmost city in the mainland of China, Zhanjiang is only one sea away from Hainan, they are close to each other in culture, geography, rich in tourism resources and distinctive product features. Both of them have good conditions for developing coastal tourism and winter vacation tourism. It is the common wish of both sides to promote the regional tourism integration of Qiongzhou Strait and build a tourism destination of Qiongzhou Strait. In recent years, under the guidance of the two governments, the two sides have carried out a lot of tourism cooperation, and the basic cooperation mechanism has been established. But at the same time, it also faces the problems of imperfect tourism infrastructure, homogenization of tourism products, imperfect tourism cooperation mechanism and so on. Therefore starting from Zhanjiang, this paper hopes to use Hainan free trade port, international tourism island and other policies to explore how to better explores the appropriate path for the integrated development of tourism between Zhanjiang and Hainan, thus enhancing the popularity and competitiveness of Qiongzhou Strait Tourism at home and abroad.
\end{abstract}

Keywords: Tourism Cooperation, Hainan, Zhanjiang, Tourism Brands, Cooperation Mechanism

\section{Introduction}

Zhanjiang and Haikou are located on both sides of Qiongzhou strait, facing each other across the sea. Zhanjiang has a relatively low level of tourism development, but it has rich tourism resources, low tourism development costs, and broad tourist market, so it has a large space for future development. The tourism industry in Hainan is relatively mature, and has accumulated rich experience in scenic spot development, talent training, which is worth learning from. It is of great significance to launch tourism cooperation between Zhanjiang and Hainan: Integrate the advantageous tourism resources of the two places to generate aggregation effect and promote the upgrading of the tourism industry structure of the two places; Enhance the popularity and competitiveness of Qiongzhou strait tourism at home and abroad, attract tourists to the greatest extent, promote the sustainable development of zhanqiong tourism; In particular, it can bring Zhanjiang into the policy extension area of Hainan international tourism island, promote the high-quality development of Zhanjiang's tourism industry, and promote the upgrading of Zhanjiang's industrial structure.

\section{Current Status}

Tourism is a traditional industry of both Zhanjiang and Hainan. With the long-term promotion of governments and enterprises, certain success has been achieved:

\subsection{Establish a Normalized Regional Tourism Cooperation Mechanism}

In 2007, Qiong-zhan regional tourism cooperation organization was established and the agreement of Qiong-zhan regional tourism cooperation alliance was signed, which played an active role in the supervision of tourism market and the information exchange of tourism services. [1] The organization has developed a system of joint meetings to conduct regular coordination and research on tourism cooperation between the two sides. In 2016, led by the government, Zhanjiang and Haikou tourism associations signed a strategic cooperation agreement, marking the transformation of tourism cooperation from government-led 
cooperation to cooperation between enterprises and civil societies. In 2018, 15 cities and counties in the Beibu gulf city cluster jointly signed the tourism cooperation framework agreement and established the Beibu gulf tourism promotion alliance. Based on these cooperation mechanisms, Zhanjiang and Hainan actively integrate tourism resources, develop tourism products and promote regional tourism cooperation.

\subsection{Develop Tourism Products for One-trip Multi-station Tourist Routes}

In recent years, a number of distinctive scenic spots such as Jinshawan coastal tourist area, Dinglongwan international ocean resort and Guilinyang national tropical agriculture park have emerged, greatly enrich the tourism product portfolio of Qiongzhou strait regional. Among them, Leiqiong global geopark, which was established jointly by two sides, has been approved as a national AAAA level scenic spot and popular science education base for teenagers. In 2017, more than 10 one-way and multi-stop tourism products with the theme of "Celebrating the new year in Zhanjiang ", "going all the way south to see the sea" and "rural tourism photography" have been launched, which have won high praise from the market. [2]

\subsection{Promote and Publicize Tourism Products}

On the basis of joint planning and design of tourism routes, further linkage promotion of tourism products, efforts to enhance the influence of tourism brands. Since 2016, Zhanjiang and Hainan have held at least two tourism promotion conferences every year to promote regional tourism products and explore tourist market in the pearl river delta, east China, northeast China, southwest China and northwest China. Thanks to the positive measures taken by the two cities, the number of tourists received by Zhanjiang has been increasing year by year in recent years. In 2020, Zhanjiang city received 60.22 million tourists, up $16.4 \%$ year on year. Tourism revenue reached 60.1 billion yuan, up $17.6 \%$ year on year. [3] According to the big data monitoring of China mobile, in 2020 there were about 10,113,100 tourists from outside the Guangdong province, among then, the top five provinces were Guangxi, Hainan, Yunnan, Sichuan and Hunan. There are about 15.2088 million tourists from the Guangdong province, and the top five cities are Guangzhou, Maoming, Shenzhen, Foshan and Dongguan. [4, 5]

\section{Problems}

Although Zhanjiang and Hainan have carried out some cooperation activities, these activities are limited to the low level, deep cooperation such as policy and industry integration have not been involved. The following problems exist:

\subsection{Policy Differentiation}

The administrative levels between Zhanjiang and Hainan are different and there are differences in the preferential policies or the policy support of the superior government departments. Since the proposal of Hainan international tourism island, a series of policies have been issued by the state and Hainan province respectively, as shown in table 1. For example, in terms of investment and financing, the state has endowed Hainan with the Western development policy, supporting qualified tourism enterprises to issue corporate bonds and set up tourism industry investment fund, while Zhanjiang has no such preferential policies.

Table 1. Comparison of national and provincial policies on Hainan international tourism island construction. [6-7]

\begin{tabular}{|c|c|c|}
\hline Policy level & Policy type & Content of the policy \\
\hline \multirow{4}{*}{ National level } & $\begin{array}{l}\text { Investment and } \\
\text { financing }\end{array}$ & $\begin{array}{l}\text { When allocating investment from the central budget and other special investment from the central government, Hainan } \\
\text { will be given the policy of large-scale development of the western region. We will support eligible tourism enterprises in } \\
\text { issuing corporate bonds. Establish a tourism investment fund. }\end{array}$ \\
\hline & $\begin{array}{l}\text { The fiscal and } \\
\text { taxation }\end{array}$ & To increase the balance of Hainan's overall transfer payments. \\
\hline & Land & $\begin{array}{l}\text { We will scientifically revise and compile the master plan for land use, implement the strictest system for protecting farmland } \\
\text { and conserving land, strictly implement the land use control system, coordinate and ensure the development of various land use } \\
\text { needs for Hainan international tourism island, and promote integrated land management between urban and rural areas. }\end{array}$ \\
\hline & Other & $\begin{array}{l}\text { We will actively introduce powerful large tourism enterprises at home and abroad, and gradually cultivate a number of } \\
\text { key tourism enterprises and well-known brands. We will implement open and convenient immigration control measures. }\end{array}$ \\
\hline \multirow[t]{3}{*}{$\begin{array}{l}\text { Provincial } \\
\text { level }\end{array}$} & $\begin{array}{l}\text { Investment and } \\
\text { financing }\end{array}$ & $\begin{array}{l}\text { We will make full use of the existing and expanded capital channels, innovate investment and financing modes, build and } \\
\text { improve Hainan tourism investment and financing platform, and create conditions for all kinds of capital to participate in } \\
\text { the development and construction of Hainan international tourism island. } \\
\text { The general plans for land use shall be scientifically revised and compiled, and a regular evaluation and adjustment } \\
\text { mechanism shall be implemented for the general plans for land use on a trial basis, provided that the quantity of } \\
\text { cultivated land, the area under the protection of basic farmland and the total scale of construction land assigned by the } \\
\text { state are not breached. }\end{array}$ \\
\hline & $\begin{array}{l}\text { Sea area and } \\
\text { island } \\
\text { management }\end{array}$ & Plan and develop marine economy scientifically, strengthen intensive and efficient utilization of Marine resources. \\
\hline & Other & To coordinate and implement the price policy of water, electricity and gas for hotels and general industrial enterprises. \\
\hline
\end{tabular}

In addition, Hainan has provincial-level authority in the formulation or adjustment of some policies for the development of tourism, but Zhanjiang does not. The difference of policy and administrative level is the biggest obstacle for Zhanjiang to develop tourism and connect with Hainan. Although Zhanjiang was designated as the sub-center 
of Guangdong province and gained some provincial authority, relevant departments should take the initiative to turn the policy dividend into the driving force of Zhanjiang's tourism development.

\subsection{Serious Homogeneity of Tourism Products}

Although constructing a lot of new tourist attractions, Zhanjiang's overall quality is not high, the phenomenon of tourist attractions' homogeneity is serious. Most of the scenic spots in Zhanjiang make beach or ocean as their selling points, with no outstanding features. They are similar to the well-known resort resources in Hainan and Beihai, which greatly reduce the attraction to tourists. In addition, the tourism products and routes jointly designed and developed by the two places are relatively single, and the scenic spots lack connotation and distribution, which makes it difficult to improve the tourist experience. Taking the Leqiong global geopark as an example, this scenic spot is jointly built by Zhanjiang and Haikou with valuable geological resources such as maar lake and volcanic rock, which was approved as the "world geopark" by UNESCO in 2006. However, the management and development of it is poor, lacking unified planning and publicity. The design features of the scenic spots are not obvious and there is a lack of "story", which fails to make them into influential products.

In terms of publicity and promotion, although the two sides have carried out many promotion activities, the influence is small, and the publicity method is still dominated by traditional media. According to data from Ctrip's booking system, only 30 percent of tourists to Hainan during the Spring Festival in 2019 chose to stay in Zhanjiang, which has not changed the awkward situation that tourists to Hainan only use Zhanjiang as a transit point to Hainan. [8] Zhanjiang has also tried to organize activities such as the Xuwen pineapple cultural tourism festival with Haikou, but these activities are generally small in scale, monotonous in form and lack of influence, so they fail to play a good role in brand promotion. Therefore, it is urgent to plan some influential international activities or events to enhance brand awareness.

\subsection{Imperfect Tourist Facilities}

The basic supporting facilities of tourist attractions lag behind seriously. Taking the South Pole village of Xuwen county as an example, this scenic spot is located in the southernmost part of the mainland of China. However, due to the lack of funds, the related tourism supporting facilities are difficult to meet the needs of tourists for leisure. In terms of dining, South Pole village has abundant seafood materials and the price is cheap, but there is no high-standard restaurant, which affects the dining experience of tourists. And there is no shopping place in the village, and the commodities sold there are mainly agricultural and sideline products with low economic added value. As for entertainment, there are only monotonous attractions such as beaches and lighthouses, lacking attractive entertainment facilities and festival activities. Many tourists complain that they have nothing to do in the evening. In terms of transportation, there is no special tourist road, which means it takes long time to pass through densely populated villages and towns. Traffic jams occur from time to time, and there are safety risks. In addition, the number of self-driving camps (tent campsites) in Zhanjiang area is small, which affects the experience of self-driving tourists. Sea-crossing ferries are greatly affected by the weather, which leads to the fluctuation of sea-crossing time. The problem of berth shortage occurs sometime. The quality of ferries is uneven, some ships have narrow cabins, uncomfortable seats and no recreational facilities for tourists, which seriously affect the tourist impression.

\subsection{Lack of High-quality Tourism Talents}

Lack of high-quality tourism practitioners is an important bottleneck to limit the development of tourism in Zhanjiang and Hainan. Comparatively speaking, the shortage of tourism talents, especially professional tour guides, is more prominent in Zhanjiang. At present, there are few colleges and technical secondary schools offering tourism-related majors in Zhanjiang, and they are all majors below the undergraduate level. There are no master's degree programs in tourism management. Most of the city's tourism practitioners are from non-professional backgrounds and lack professional knowledge structure. Tourism enterprises also have low requirements for the entry of tourism practitioners. Most of them have not received professional pre-job training. There is a shortage of middle and senior management talents with professional knowledge, and it is difficult to provide tourists with high-quality tourism services. At the same time, the tourism industry is characterized by high intensity of work, low salary and limited development space, which leads to frequent outflow of personnel and unstable workforce, which restricts the rapid and healthy development of tourism in Qiongzhou strait region.

\subsection{The Tourism Cooperation Mechanism Is Not Sound}

Although the two sides have signed some agreements, a mature and standardized cooperation mechanism has not yet been established, resulting in the randomness of bilateral cooperation. The inter-regional flow of tourism resources, the restructuring of tourism industry cooperation and the collectivization development of tourism regions have made slow progress. Although the two places have established a preliminary joint meeting system, regional tourism cooperation involves multi-level management, and there is no special tourism cooperation management body to coordinate, which is prone to create confusion and prevarication. In addition, there are differences in location and economic basis between the two places, so the cooperation will lead to interest conflicts. Therefore, it is necessary to build a corresponding mechanism to coordinate the interests of both sides.

\subsection{The Strength of Tourism Enterprises Needs to Be Improved}

Few tourism enterprises in the two places has cultural 
tourism industry qualifications, let alone well-known leading enterprises. Comparatively speaking, Hainan's tourism industry development is relatively better. In addition to the traditional travel agencies, transportation companies, hotels and catering enterprises, a number of excellent exhibition tourism, cultural tourism and other new forms of tourism enterprises have emerged, among them, Haikou Tourism Culture Investment Holding Group Co., Ltd., Huajin tourism industry, etc. are representative. The development of tourism industry in Zhanjiang city is relatively backward, and its scale and maturity are not as good as Hainan. Few companies are engaged in tourism planning, health tourism, cruise tourism and other new forms of business. Most enterprises are mainly small and medium-sized private enterprises. These enterprises have limited influence.

\section{Suggestions}

In view of the existing problems, the following suggestions are put forward to promote the in-depth cooperation between Zhanjiang and Hainan.

\subsection{Strive for the Complementarity of Relevant Policies}

At the national level, Hainan's international tourism island construction has four policy objectives: the pilot zone for comprehensively deepening reform and opening up, the national ecological civilization pilot zone, the international tourism consumption center, and the national major strategic service guarantee zone. The policy goal of Hainan province is to be a world-class tropical island resort. Based on the construction of provincial sub-center, Zhanjiang should comprehensively study the connection of relevant policies between the two places. First of all, we should strive for the support of Guangdong provincial government, take the initiative to coordinate with Hainan to undertake national policies, coordinate provincial policies, and delegate some provincial powers. Actively strive to introduce the following policies: Qiongzhou cross-strait tourism planning, major tourism project approval and other top-level design unified planning policy; Qiongzhou cross-strait cruise industry development support policy; The tourism visa opening policy of Leizhou peninsula and the tax exemption policy of Leizhou peninsula as an extension of the tax exemption policy of Hainan island.

Secondly, from the perspective of tourism development, it is necessary to carry out relevant policies in the fields of land use, sea area and island management, capital introduction and financing, infrastructure supporting construction and other fields. For example, in terms of attracting investment and financing, we should build tourism investment and financing platform, reduce taxes and other policies, and encourage relevant tourism enterprises to set up companies in Zhanjiang with Hainan headquarters; We will strive for policy support from Guangdong Province, set up Zhanjiang and Qiongzhou tourism industry investment funds, and support qualified tourism enterprises to issue corporate bonds. Based on the policy objectives of Zhanjiang national military civilian integration industrialization demonstration base and Hainan national strategic service support area, the relevant policies of jointly building military civilian integration development comprehensive service platform and logistics socialization service support center were issued to jointly create a new tourism destination - national defense education base in south China (military port, satellite launch education base). At present, Hainan has further relaxed demand for the development of the tax-free industry. Zhanjiang should actively act to win the policy support of Guangdong Province and relevant ministries and commissions, and incorporate Xuwen port area into Hainan island free expansion zone. In addition, since culture is the soul of tourism and the basis of cultural identity between the two places, Zhanjiang should strive for policy support from Guangdong province and become the pioneer and experimental area for provincial-level cultural and tourism cooperation between Guangdong and Hainan provinces. Drawing lessons from the Shenzhen Window of the world model, the intangible cultural heritage projects in Leizhou Peninsula such as East island dragon dance, Suixi lion dance, Leizhou stone dog, Leizhou song, Zhanjiang Nuo dance and Lei opera should be presented jointly, thus building it into a tourism complex of Zhanjiang business card. [9]

\subsection{Create Distinctive Tourism Brands}

In view of the commonness of tourism resources between Zhanjiang and Hainan, we can launch tourism products with multiple themes, including marine leisure vacation, health care (winter rest) medical, cruise yacht, agricultural leisure, geological research and so on. For example, through ticket exchange (as the weak side of tourism development, referring to the practice of Guizhou and Guangxi-free tickets for targeted tourist sources, it is suggested that Zhanjiang implement the whole territory free ticket policy for Hainan tourists to Zhanjiang or further cooperate with other cities in the Beibu Gulf to implement the Beibu Gulf city tourism pass) [10], joint science exhibitions and science and technology festivals, Leiqiong World Geopark will be built into an influential youth study tour and science education base at home and abroad. In view of the original fishing villages around Zhanjiang and Hainan, we should take the road of joint development of high-end characteristic B \& B villages (a global tourism mode of cooperation between tourism companies and local communities). Zhanjiang should learn from the management concept of Xuwen South pole village artists' tribal homestay: Take the slow life of fishing village as the theme, combining with literary creation, marine science popularization, sea crossing battle sites and other elements, through the organization of fishing, production of seafood and related art works, red tourism and other activities, tourists can deeply experience the local island life and culture, thus transforming the marine culture, marine science popularization education and marine experience into tourism products. Develop marine cruise products connecting Nansan island, Longhaitian and Hainan island, highlight the cultural theme of Marine Silk Route and enhance the influence of 
Qiongzhou strait tourism brand.

In terms of brand promotion, we should continue to strengthen the marketing of tourist sources (For example, taking advantage of the role of Zhanjiang in hosting Hubei tourists during the period of COVID-19, as an opportunity to publicize Zhanjiang in the central and western regions), strengthen the cooperation with Ctrip, Fliggy and other tourism platforms, and vigorously tap the IP stories behind the scenic spots; The integration of culture and tourism should be strengthened, the traditional culture and regional culture should be explored, and the culture should be transformed into attractive tourism products by using policy advantages (For example, we should excavate the homologous elements of Lei opera and Qiong opera, integrate the contents with the characteristics of the times, and create the distinctive drama brands of the two places). We will combine scenic spots with local intangible cultural heritage, jointly plan cultural and creative activities and festivals such as Haikou Spring Festival, midsummer art season, attract media reports and public participation, and expand the brand awareness of tourism in both places. By referring to the brand promotion concept of the Palace Museum, it cooperates with FMCG products, movies and TV dramas, mobile game, variety shows and other marketing activities to establish a youthful and fashionable tourism brand image, and regularly holds ocean music festival, star concert, sports competition and other activities to attract traffic and enhance exposure. [11]In the choice of publicity media, we should make full use of modern publicity methods, utilize the popular Tiktok and other short video platforms and naked eye AR, VR video, cooperate with internet celebrity to carry out online live broadcasting, attract young consumers to travel card recommendation, and achieve the purpose of improving the visibility of Zhanjiang tourism.

\subsection{Improving Tourism Supporting Facilities}

In view of the problem of backward supporting facilities, the government and enterprises should increase investment, actively attract investment and promote the construction of supporting facilities for eating, living, entertainment, shopping and transportation in scenic spots. Learning from Hainan, we will improve public service facilities such as tourist traffic signs, public toilets, and self-driving travel camps to improve the level of self-driving travel services. Xuwen port area is an important passage connecting Zhanjiang and Hainan. In order to improve the traffic efficiency between the two places, it is necessary to increase ship berths, construct cruise ship ports and accelerate the construction of seaplanes, fast passenger ships and high-speed rail, so as to create a "half-hour three-dimensional traffic circle" in Qiongzhou strait. A Municipal Tourist Distribution Center and service center will be set up in Nanshan operation area of Xuwen port area to provide "one-stop" services such as scenic spot connection, scenic spot tickets and hotel reservation, tourist route guidance, emergency rescue, etc., so as to ensure that expressway, high-speed rail and railway can directly reach Nanshan port, radiate western Guangdong, and build the South Gate of Guangdong tourism.

\subsection{Strengthen Tourism Personnel Training}

First of all, the government should plan the demand for tourism talents. Relevant departments should speed up the preparation of Zhanjiang tourism talent team development plan, put the talent team construction in a more prominent position. Combined with the reality of Zhanjiang, in the next few years, we should focus on increasing the cultivation of tour guides, commentators, data management, tourism marketing and other aspects of talent. Secondly, Colleges and universities in Zhanjiang are encouraged to set up tourism management related majors to train local tourism talents. To keep up with the changes in the tourism market, the tourism talent training plan is constantly improved, and relevant courses such as exhibition planning and tourism information management are added to cultivate tourism talents in line with the market demand. [13] Through cooperation with hotels, scenic spot management companies, travel agencies and other tourism units, we will build collaborative innovation center, innovation and entrepreneurship base and other carriers, and establish a talent training mode of industry education integration and collaborative education. Third, enhance the role of tourism enterprises in screening professional talents. Tourism enterprises should raise the entry threshold of employees, encourage employees to participate in various on-the-job training, actively expand the growth and promotion space of tourism talents, and provide more favorable salary and welfare treatment for employees. [14] In order to meet the demand for talents with the rapid development of local tourism, we should intensify the introduction of talents, implement the policy of settling talents, and establish a talent evaluation system applicable to both places.

\subsection{Establishing a Long-term Mechanism for Tourism Cooperation}

First, through Qiongzhou strait tourism cooperation fund and intergovernmental transfer payment, the costs incurred in the cooperation shall be reasonably compensated. At present, the development of tourism industry in the two places is unbalanced, so Hainan should give full play to Zhanjiang's leading role, subsidize the interests of the relatively weak regions, and ensure the persistence of cooperation. On the other hand, support tourism infrastructure construction and tourism product development and promotion.

Secondly, in view of the problem of multi-headed management of tourism cooperation, we should establish corresponding regional coordination institutions to follow the example of the "cooperation joint conference" in the pearl river delta, perform their duties in terms of tourism cooperation supervision, regulation and policy formulation and coordination, and cooperate with universities and scientific research institutions to strengthen theoretical research and guide practice related to tourism cooperation.

Third, the information sharing between cities is also the basis for the smooth development of cooperation. It is necessary to build a Qiongzhou strait tourism information sharing platform as soon as possible, release the relevant 
information and policies in the region in real time, promote the information exchange and sharing between the two places, so as to ensure the smooth development and continuity of tourism cooperation.

\subsection{Strengthen the Cultivation and Development of Tourism Enterprises}

Zhanjiang should actively create a favorable environment for the development of small and medium-sized tourism enterprises: establish a financing system suitable for the characteristics of small and medium-sized enterprises, encourage overseas and social capital to participate in tourism financial services, and provide efficient financial services for tourism enterprises; accelerate innovation in the integration of tourism and the Internet, encourage mass entrepreneurship, develop online tourism shopping and catering service platforms, and standardize the market for online tourism car rental and other new forms of business. We will introduce effective tax relief policies to help start-ups reduce their burdens and grow rapidly.

In view of the characteristics of "scattered, small, weak and poor" of tourism enterprises, the network operation mode of transnational corporations is used for reference. Through merger and reorganization, enterprises in the two regions are encouraged to take the road of group or chain development, so as to realize greater scope of resource sharing and improve resource utilization efficiency. At present, the consumption level, land price and environmental protection requirements are generally low in Zhanjiang region. Coupled with the policy expectation of Hainan province to ban the use of oil-fueled vehicles on the island in 2030, Zhanjiang should attract Hainan leading tourism enterprises to set up in Zhanjiang, carry out cross-regional tourism business, and enhance the overall strength of the regional tourism industry by exerting the scale effect. At the same time, we will actively promote the establishment of Chinese town project in Zhanjiang, and build a high-end service urban functional area and urban landmark group in Zhanjiang.

\section{Conclusion}

Hainan and Zhanjiang are two poles of the "one nuclear and two polar" framework in Beibu Gulf Urban Agglomeration. To speed up the integrated development of Qiongzhou Strait is not only the need for the two places to actively serve and connect with the national strategy, but also a major opportunity to promote the economic development of the two cities. Although a series of activities have been carried out to promote the integrated development of tourism, the results of these cooperation are limited. At present, there are still some important problems, such as imperfect cooperation mechanism, lack of tourism talents and so on. Under the background of national policies such as Beibu Gulf Urban Agglomeration and Hainan free trade port, we can carry out deeper tourism exchanges and cooperation:(1) Strive for the complementarity of relevant policies; (2) Jointly build tourism brand and develop tourism market; (3) Actively promote the interconnection and improvement of infrastructure between the two places; (4) Establish and improve the mechanism of attracting and cooperative training of tourism talents; (5) Innovate tourism cooperation mechanism and construct effective cooperation platform; (6) Strengthen the cultivation and development of tourism enterprises, and make the industrial cluster stronger and bigger. In the near future, the popularity and competitiveness of Qiongzhou Strait Tourism at home and abroad will be greatly enhanced to attract tourists to the maximum extent and realize the sustainable development.

\section{References}

[1] Cheng jin, $\mathrm{Lu}$ lin. Research of the difference of regional tourism Economy in Anhui pronvince. Journal of ANHUI normal university. Vol. 33. No. 1. Jan. 2010.

[2] Liu, Y., Lai, L., \& Yuan, J. (2020). Research on Zhanjiang's Leisure Sports Tourism Development Strategy in Coastal Recreational Areas. Journal of Coastal Research, 111, 248252.

[3] Yafen HUANG, Hua QUAN (2019). Evaluation on Urban Tourism Competitiveness of Beibu Gulf Rim Based on the Entropy Approach. Asian Agricultural Research. 2019; 11 (10): $1-10$.

[4] Zhang R. Changing Beach Destination Image Schemas through Storytelling: A Study of Hainan Island, China. 2018. Accessed April 16, 2021. https://search.ebscohost.com/login.aspx?

[5] Tian jipeng. Research on regional deferrence of shanghai tourism industry: Based on relations among tourism resources enterprises, policies and tourism economy [J]. Tourism science. Vol 25, No 3. Jun, 2011.

[6] Cong jiaqi. An analysis on the reginal differences of Hebei tourism development [J]. Journal of Hebei normal university. vol 33 no. 4. Jul. 2009.

[7] LIANFENG Z, DANKO YI, ZHUANQING C. International Cooperation of Ukraine Tourism based on "The Belt and Road Initiative." Accounting \& Finance / Oblik i Finansi. 2020; (89): $140-147$.

[8] Thao VT, von Arx W, Frölicher J. Swiss Cooperation in the Travel and Tourism Sector: Long-term Relationships and Superior Performance. Journal of Travel Research. 2020; 59 (6): 1044-1060. K.

[9] Zhifei LI, Chenchen Zhang. International Tourism Cooperation Based on "the Belt and Road": Strategy and Path $[\mathrm{J}]$. Confrontation and Cooperation: 1000 Years of Polish-German-Russian Relations, 2020, 6 (1).

[10] Nazar Hilal. Tourism in the Gulf Cooperation Council Countries as a Priority for Economic Prospects and Diversification [J]. Journal of Tourism \& Hospitality, 2020, 9 (7).

[11] Juan Zhang. "Research on the Cultural and Tourism Cooperation Between Gansu Province and Russian-speaking Countries Along the Belt and Road Exploration of Local Russian Language Talents Cultivation". Proceedings of the 2020 International Conference on Language Communication and Culture Studies (ICLCCS2020). Ed. Atlantis Press, 2020, 174-180. 
[12] J. Yvette SÃ $i n c h e z$ Garc Ãa, Juan E. NÃ $\tilde{A}^{\circ} \tilde{A} \pm$ ez RÃos, Carlos LÃ $\tilde{A}^{3}$ ez Hern $\tilde{j}$ indez. Systemic complementarity, an integrative model of cooperation among small and medium-sized tourism enterprises in Mexico [J]. International Journal of Business Innovation and Research, 2020, 23 (3).

[13] Knight David W., Nian Wang, Chen Elaine. Launching an online graduate degree for tourism management in China: lessons in Chinese-foreign cooperation [J]. Journal of Teaching in Travel \& Tourism, 2020, 20 (4).
[14] Yongquan Li, Rui Li, Wenqi Ruan, Chih-Hsing Liu. Research of the Effect of Tourism Economic Contact on the Efficiency of the Tourism Industry [J]. Sustainability, 2020, 12 (14).

[15] Zhou Chen. Reflection and Innovation on the Practice Mode of Tourism Management Major in Colleges and Universities Based on School-Enterprise Cooperation [J]. Frontiers in Economics and Management 2020, 1 (5). 